\title{
INCORPORATION OF RADIOIRON INTO MYOGLOBIN IN AN IN VITRO SYSTEM *
}

\author{
By GERALD T. PERKOFF, $\dagger$ HERBERT C. SCHWARTZ $\$$ AND FRANK H. TYLER
}

\author{
(From the Department of Medicine and the Laboratory for the Study of Hereditary and Meta- \\ bolic Disorders, University of Utah College of Medicine, Salt Lake City, Utah)
}

(Submitted for publication December 29, 1958; accepted June 1, 1959)

It is known that avian erythrocytes $(1,2)$, bone marrow (3), liver, muscle and kidney (4) are capable of synthesizing heme in vitro. Glycine, $\delta$-aminolevulinic acid, porphobilinogen and protoporphyrin $(2,5-7)$ are among the known intermediates in this process. Per unit weight, muscle is one of the least active tissues in the synthesis of heme, and few studies have been made of the process in this tissue.

Previously $(8,9)$, we have described procedures for the isolation of myoglobin which were found suitable for the preparation of this protein for physical characterization. In order to gain further information about the metabolism of myoglobin, these procedures for myoglobin isolation have been applied to a study of radioiron incorporation into myoglobin in dog and human muscle. In these studies, the myoglobin heme was labeled with $\mathrm{Fe}^{59}$ in a system similar to that described by others for avian erythrocytes (2). By this means it has been possible to demonstrate that extracts of dog and human muscle can use radioiron for the formation of myoglobin. It appears that heme synthesis in muscle is similar in many ways to that in other tissues.

\section{METHODS}

Preparation of extracts and incubation mixture. Mongrel dogs were sacrificed by the intracardiac injection of 10 per cent pentobarbital. Three hundred to 500 $\mathrm{Gm}$. of muscle was dissected from the hind limbs, trimmed free of fat and placed in a beaker over ice. The muscle was ground twice in an electric meat grinder. The brei was mixed with an equal volume of $0.15 \mathrm{M}$ potassium chloride containing approximately $20 \mathrm{mg}$. each of penicillin and streptomycin and allowed to stand for 12 to

\footnotetext{
* This study was supported in part by research grants from the Muscular Dystrophy Associations of America, Incorporated, and the National Institutes of Health, United States Public Health Service.

$\dagger$ John and Mary R. Markle Scholar in Medical Science. $\ddagger$ Postdoctoral Research Fellow, National Heart Institute, United States Public Health Service.
}

18 hours. Shorter extraction periods were associated with less iron incorporating activity in the final extracts. Sodium fluoride, $0.1 \mathrm{M}$, a concentration which has been shown to have no effect on heme synthesis in avian erythrocytes (10), was added to the extracting fluid to inhibit glycolysis. This mixture was homogenized in a Waring blendor for three minutes. All of these procedures were carried out at $4^{\circ} \mathrm{C}$. Centrifugation at 1,500 $\mathrm{rpm}$ for 30 minutes $(500 \times \mathrm{G})$ then was carried out at room temperature.

The incubation mixtures were prepared in $50 \mathrm{ml}$. Erlenmeyer flasks by adding the following: $14 \mathrm{ml}$. of the supernatant fluid from the dog muscle homogenate: $4 \mathrm{ml}$. of Tris [Tris (hydroxymethyl) aminomethane] buffer (final concentration $0.5 \mathrm{M}$ Tris) at $\mathrm{pH} 7.7 ; 1 \mathrm{ml}$. of ferrous $^{39}$ citrate $(1.0$ to $2.0 \mu \mathrm{c}$., specific activity 1 to 3 mc. per $\mathrm{mg} . \mathrm{Fe}$ ) ; and either $1 \mathrm{ml}$. of 0.9 per cent sodium chloride or other additive according to the experimental protocol. All incubations were carried out in air in a Dubnoff shaker at $37^{\circ} \mathrm{C}$., $70 \mathrm{cpm}$, for four hours. Further radioiron incorporation was then stopped by the initial step in the myoglobin isolation procedure, the addition of one-fourth the reaction volume of saturated basic lead acetate.

Myoglobin was isolated by differential solubility in phosphate buffer as described previously $(8,9)$. In order to avoid contamination of the myoglobin with radioactive iron phosphate complexes and to concentrate the myoglobin for counting, a special procedure was used after the hemoglobin had been precipitated with concentrated phosphate buffer. The samples were shaken with $10 \mathrm{ml}$. of chloroform for 20 minutes in a Kahn shaker. This precipitated the myoglobin at the interphase as a fluffy, readily dispersed precipitate. After the supernatant solution had been discarded, the myoglobin layer was punctured with a wooden rod to allow egress for the chloroform. The myoglobin precipitate was then washed six times with 1 per cent trichloroacetic acid. The final wash was nonradioactive and contained less than $0.5 \mu \mathrm{g}$. per $100 \mathrm{ml}$. of phosphate. After carrying out the last wash in a counting vial, the radioactivity of the samples was measured in a well-type scintillation counter.

Since the interpretation of the results to be presented is dependent on the demonstration that myoglobin prepared by this method is, indeed, essentially free of hemoglobin, several experiments were carried out to demonstrate this fact. Some of these studies have been presented previously (9).

By measuring optical density of cyanide-treated dog 
TABLE I

Demonstration of removal of hemoglobin from myoglobin in dog muscle extracts *

\begin{tabular}{|c|c|c|c|c|c|c|c|c|c|c|}
\hline \multirow[b]{2}{*}{ Sample } & \multirow{2}{*}{$\begin{array}{l}\text { Hemoglobin } \\
\text { added }\end{array}$} & \multirow{2}{*}{$\begin{array}{c}\text { Total } \\
\text { hemoglobin }\end{array}$} & \multirow{2}{*}{$\begin{array}{c}\text { cpm } \\
\text { added }\end{array}$} & \multirow{2}{*}{$\begin{array}{c}\text { Myoglobin } \\
\text { isolated }\end{array}$} & \multicolumn{3}{|c|}{$\begin{array}{l}\text { Counting rates } \\
\text { myoglobin samples } \\
\text { cpm }\end{array}$} & \multirow{2}{*}{$\begin{array}{l}\text { Hemoglobin } \\
\text { remaining }\end{array}$} & \multirow{2}{*}{$\begin{array}{l}\text { Hemoglobin } \\
\text { remaining }\end{array}$} & \multirow{2}{*}{$\begin{array}{l}\text { Myoglobin } \\
\text { in final } \\
\text { samples }\end{array}$} \\
\hline & & & & & Total & Net & $\mathrm{S}$ & & & \\
\hline & $m g$. & mg./sample & & $m g$. & & & & $\%$ & $m g$. & $\%$ \\
\hline 1 & 0 & 25 & 0 & 19.0 & 163 & 0 & & & & \\
\hline 2 & 0 & 25 & 0 & 20.0 & 163 & 0 & & & & \\
\hline 3 & 27 & 52 & 1,944 & 18.8 & 172 & 8 & \pm 2.3 & 0.47 & 0.24 & 98.7 \\
\hline 4 & 27 & 52 & 1,944 & 18.7 & 181 & 17 & \pm 2.3 & 0.87 & 0.45 & 97.6 \\
\hline 5 & 54 & 79 & 3,888 & 19.4 & 194 & 30 & \pm 2.4 & 0.77 & 0.61 & 96.9 \\
\hline 6 & 54 & 79 & 3,888 & 17.6 & 190 & 26 & \pm 2.4 & 0.67 & 0.52 & 97.0 \\
\hline 7 & 135 & 160 & 9,720 & 18.9 & 225 & 61 & \pm 2.6 & 0.63 & 1.0 & 94.7 \\
\hline 8 & 135 & 160 & 9,720 & 17.5 & 216 & 52 & \pm 2.6 & 0.53 & 0.85 & 95.1 \\
\hline 9 & 270 & 295 & 19,440 & 19.2 & 211 & 47 & \pm 2.5 & 0.24 & 0.71 & 96.3 \\
\hline 10 & 270 & 295 & 19,440 & 20.0 & 213 & 49 & \pm 2.5 & 0.25 & 0.74 & 96.3 \\
\hline
\end{tabular}

* Samples were composed of $16 \mathrm{ml}$. crude muscle extract and $2.5 \mathrm{ml}$. water or hemoglobin solution. All samples were counted for 16,384 counts. Hemoglobin specific activity $=72 \mathrm{cpm}$ per $\mathrm{mg}$.; hemoglobin content of crude extract before additions $=25 \mathrm{mg}$. per $16 \mathrm{ml}$.

muscle extract at $540 \mathrm{~m} \mu$ before and after the addition of phosphate buffer, an estimate of the relative amounts of hemoglobin and myoglobin in the extract was obtained. These values ranged from 5 to $25 \mathrm{mg}$. of hemoglobin and 18 to $36 \mathrm{mg}$. of myoglobin per $16 \mathrm{ml}$. of extract. Accordingly, radioactive hemoglobin, prepared by aqueous hemolysis of triply-washed erythrocytes from a dog previously given intravenous ferrous ${ }^{59}$ citrate was added to identical $16 \mathrm{ml}$. samples of muscle extract prepared from another dog. The amount of hemoglobin added varied from one to 10 times the hemoglobin content of the crude extract. Myoglobin was isolated from the extracts and the radioactivity measured in the scintillation counter. The results are shown in Table I. Because the levels of radioactivity remaining in the samples were so low, long counting times were used, and the standard deviation of each sample counting rate was cal-

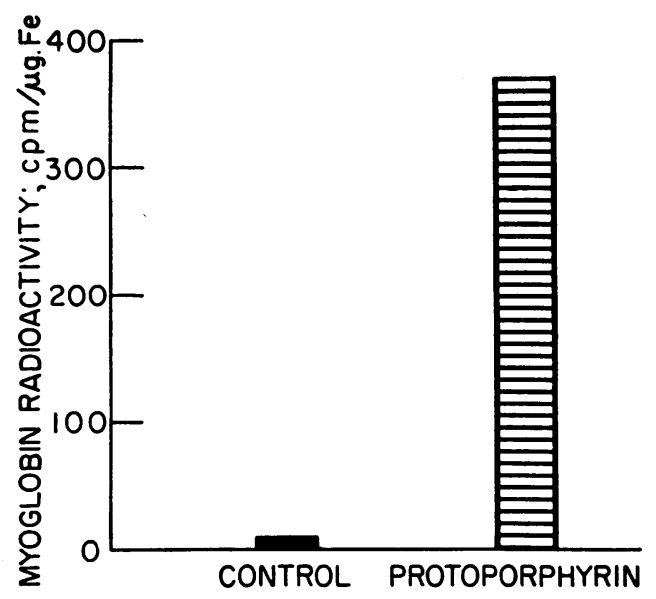

Fig. 1. The Effect of Protoporphyrin on the InCORPORATION OF RaDioiron INTO MYOglobin IN A TyPical EXPERIMENT culated according to the formula :

$$
S= \pm \sqrt{\frac{s+b}{t_{s}}}+\frac{b}{t_{b}}
$$

where $S=$ standard deviation of the sample counting rate; $\mathrm{s}=$ sample counting rate $; \mathrm{b}=$ background counting rate; $\mathrm{t}_{\mathrm{s}}=$ total time sample counted; and $\mathrm{t}_{\mathrm{b}}=$ total time background counted. These results are included in Table I.

In this experiment, myoglobin purity with reference to hemoglobin ranged from 94.7 to 98.7 per cent. In particular, at levels of hemoglobin contamination closest to the hemoglobin level of the crude extract used in the studies to be presented, the final myoglobin samples contained 97.6 to 98.7 per cent myoglobin. This experiment demonstrated effective removal of hemoglobin and secondarily showed that elaborate procedures to perfuse muscles free of blood prior to extraction were unnecessary.

After counting, the myoglobin was washed into Kjeldahl flasks for digestion and the iron content was determined by the method of Gubler and co-workers (11). Radioactivity has been expressed as cpm per $\mu \mathrm{g}$. of myoglobin iron. It should be noted that no attempt has been made to control the total iron content of each flask. This, coupled with the innate variations in the system from dog to dog, prevents comparison between absolute values of radioactivity from experiment to experiment. In order to obviate this difficulty, internal controls, in the form of extracts containing buffer and radioiron, but without protoporphyrin or other additives, have been included in each experiment.

Techniques similar to those employed in the dog studies were used in the study of human muscle. This was obtained at autopsy from two nondystrophic human subjects and two patients with myotonic dystrophy.

Protoporphyrin-9-methyl ester ${ }^{1}$ was prepared by hydrolysis in $7 \mathrm{~N}$ hydrochloric acid for 18 hours, followed

${ }^{1}$ Obtained from Monadnock Research Institution, Antrim, New Hampshire. 


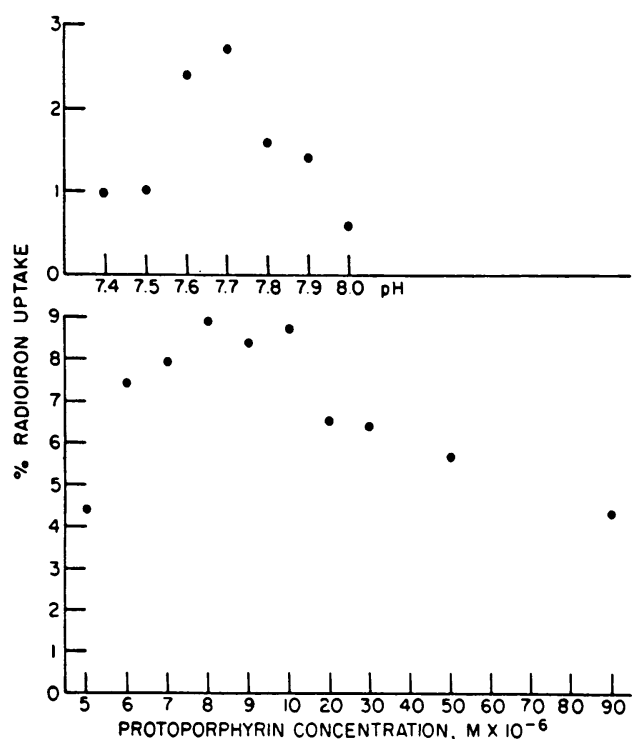

Fig. 2. The Effects of Hydrogen Ion and of PROTOPORPHYRIN CONCENTRATION ON RAdIOIRON UPTAKE INTO MYogLOBIN

by removal of excess acid in a desiccator over sodium hydroxide. The protoporphyrin hydrochloride was dissolved in $0.14 \mathrm{M}$ sodium bicarbonate prior to addition to the incubation flasks. Glycine and $\delta$-aminolevulinic acid were dissolved in water and neutralized with sodium hydroxide prior to addition to the incubation flasks. In some experiments, heme was isolated from the reaction mixtures by the method of Fischer (12) and recrystallized by the method of Shemin, London and Rittenberg (13). The radioactivity of the heme then was determined. In these experiments, the results were expressed as the percentage of added radioiron which was incorporated into heme (per cent uptake of $\mathrm{Fe}^{59}$ ) (2).

\section{RESULTS \\ Effect of protoporphyrin}

The addition of protoporphyrin to flasks incubated four hours resulted in a 10 - to 200 -fold augmentation of radioiron uptake. Zero time controls, containing protoporphyrin but not incubated, yielded nonradioactive myoglobin. A typical experiment is shown in Figure 1. In order to demonstrate whether the radioactivity of the myoglobin was due to the incorporation of $\mathrm{Fe}^{59}$ into the heme or could be attributed to nonspecific binding, the myoglobin from a reaction mixture was purified, the heme of the myoglobin was isolated and the radioactivity of the heme was determined. Of the radioiron present in the myoglobin, 95 per cent was recovered in the heme.
The effects of protoporphyrin concentration and of $\mathrm{pH}$ are shown in Figure 2. The optimal protoporphyrin concentration was $8 \times 10^{-6} \mathrm{M}$ to $1 \times 10^{-5} \mathrm{M}$, and the optimal $\mathrm{pH}$ was 7.6 to 7.7. Therefore, in subsequent studies, the assays were performed at $\mathrm{pH} 7.6$ to 7.7 and $9 \times 10^{-6} \mathrm{M}$ protoporphyrin was used.

\section{Effect of time of incubation}

Myoglobin isolated from samples after incubation times varying from 15 to 240 minutes showed rapid increase in radioactivity in the first 15 to 30 minutes (Figure 3 ) followed by a more gradual rise thereafter. Incorporation of radioactive iron into the myoglobin heme was still continuing at four hours.

\section{Effect of heat}

Since heating the muscle extract at $70^{\circ} \mathrm{C}$. for 15 minutes prior to assay altered the properties of the myoglobin to such an extent that good recoveries could not be obtained, heme isolation was used to study the effect of heat on this system. Since the heme was isolated from whole extracts, rather than from myoglobin itself, these results apply to overall heme synthesis in muscle extracts and not necessarily to myoglobin heme, per se. Under these conditions, heme synthesis was inhibited 62 per cent as compared with ' control unheated extracts.

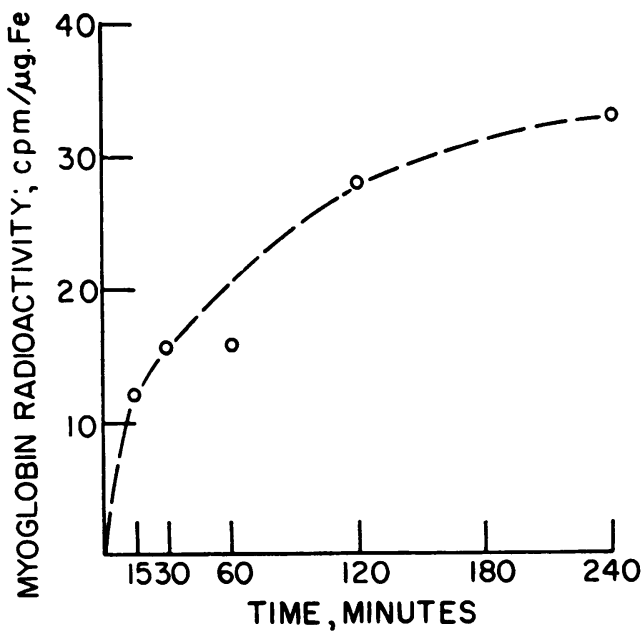

Fig. 3. The EfFect of Time on the Incorporation of RADIOIRON INTO MYOGLOBIN 
TABLE II

Effect of ultracentrifugation of muscle homogenate supernate on radioiron uptake into heme

\begin{tabular}{lc}
\hline \multicolumn{1}{c}{ Sample } & Uptake \\
\hline & $\%$ \\
Protoporphyrin & 0.5 \\
+ Fe control & 10.2 \\
Whole (initial) extract & 2.4 \\
Supernatant solution & 11.0 \\
Residue & \\
\hline
\end{tabular}

\section{Effect of ultracentrifugation}

A muscle extract .was centrifuged in a Spinco preparative ultracentrifuge at $100,000 \mathrm{G}$ for eight hours at $4^{\circ} \mathrm{C}$. The radioiron incorporation into heme was studied in uncentrifuged extract, supernatant solution and residue. Since myoglobin remains in the supernatant under these conditions, none was present in the samples of residue. Therefore, activity was determined by the isolation of heme instead of myoglobin. The data presented in Table II show that supernatant solution had much less activity than residue, which had essentially the same actvity as the initial extract.

\section{Effects of dialysis and of sulfhydryl compounds}

It has been shown that sulfhydryl groups are required for optimal activity in an avian hemolysate system for the synthesis of heme from protoporphyrin and iron $(13,14)$. For this reason, the effects of dialysis and of sulfhydryl compounds were studied in the present system.

Dialysis against distilled water, $4^{\circ} \mathrm{C}$., for 18 hours, resulted in almost complete loss of activity. The addition of cysteine to dialyzed extracts resulted in partial restoration of activity. In undialyzed extracts, cysteine addition resulted in a twofold increase in radioiron uptake. Similar results were obtained when reduced glutathione was used instead of cysteine. These data are shown in Table III.

\section{Effects of inhibitors}

The effect of $\rho$-chloromercuriphenyl sulfonic acid, a sulfhydryl inhibitor, was studied. This compound, at a concentration of $2.5 \times 10^{-3} \mathrm{M}$, resulted in 69 per cent inhibition of radioiron incorporation into the myoglobin. At a concentration of $2.5 \times 10^{-2} \mathrm{M}$, the inhibition was 97 per cent. Incubation in the presence of $1 \times 10^{-3} \mathrm{M}$ potassium cyanide resulted in complete inhibition of radioiron incorporation.

\section{Effect of glycine or $\delta$-aminolevulinic acid}

The effect of glycine and $\delta$-aminolevulinic acid on radioiron uptake was measured in the supernatant solution of a muscle homogenate. In addition, the effect of glycine alone and with succinate was studied in muscle brei. In three experiments with muscle extract, augmentation could not be demonstrated with concentrations of glycine varying from $10 \times 10^{-2}$ to $5 \times 10^{-3} \mathrm{M}$. The addition of $1 \times 10^{-4} \mathrm{M} \delta$-aminolevulinic acid led to a two- to fourfold increase in radioiron uptake in two out of three experiments (Table IV). Using the same Tris concentration for brei as was used in supernatant extracts, the $\mathrm{pH}$ of the mixtures dropped to 6.4 during incubation, and no radioiron uptake occurred. By using $1.0 \mathrm{M}$ Tris and incubating brei immediately after grinding the muscle, the $\mathrm{pH}$ could be controlled. With this technique, glycine alone increased radioiron incorporation, while glycine plus succinate gave further augmentation (Table V).

\section{Human material}

The incorporation of radioiron into myoglobin from extracts of human muscle obtained from two nondystrophic and two dystrophic subjects was studied. The autopsies were performed 12 to 20 hours after death. The data are shown in Table VI.

In the muscle extracts from all four subjects, the addition of protoporphyrin resulted in a two-

TABLE III

The effect of cysteine or reduced glutathione on uptake of radioiron

\begin{tabular}{ccc}
\hline \hline & $\begin{array}{c}\text { Undialyzed } \\
\text { extract }\end{array}$ & $\begin{array}{c}\text { Dialyzed } \\
\text { extract }\end{array}$ \\
\hline Cysteine concentration & $c p m / \mu g . F e$ & $c p m / \mu g . F e$ \\
0 & 147 & 15 \\
$1 \times 10^{-3} \mathrm{M}$ & & 87 \\
$5 \times 10^{-3} \mathrm{M}$ & 275 & 127 \\
$1 \times 10^{-2} \mathrm{M}$ & & \\
Glutathione concentration & & \\
0 & 33 & \\
$1 \times 10^{-2} \mathrm{M}$ & 70 & \\
\hline
\end{tabular}


TABLE IV

Effect of glycine and $\delta$-aminolevulinic acid on radioiron uptake in dog muscle extract

\begin{tabular}{|c|c|c|c|c|}
\hline Experiment & Substrate & Concentration & Control & $\begin{array}{l}\text { Substrate } \\
\text { added }\end{array}$ \\
\hline & & & $c p m / \mu g . F e$ & $c p m / \mu g . F e$ \\
\hline 1 & Glycine & $5 \times 10^{-3} \mathrm{M}$ & 10 & 9 \\
\hline 2 & Glycine & $5 \times 10^{-2} \mathrm{M}$ & 3 & 4 \\
\hline 3 & Glycine & $10 \times 10^{-2} \mathrm{M}$ & 3 & 2 \\
\hline 4 & $\delta$-Aminolevulinic acid & $1 \times 10^{-4} \mathrm{M}$ & 12 & 53 \\
\hline 5 & $\delta$-Aminolevulinic acid & $1 \times 10^{-4} \mathrm{M}$ & 2.5 & 2.5 \\
\hline 6 & $\delta$-Aminolevulinic acid & $1 \times 10^{-4} \mathrm{M}$ & 30 & 68 \\
\hline
\end{tabular}

fold increase in the incorporation of radioiron into myoglobin. In the muscle extracts from the one nondystrophic subject to which cysteine was added, a further twofold increase in iron uptake was observed.

\section{DISCUSSION}

It may be concluded fom these studies that the supernatant solution from a dog muscle homogenate is capable of radioiron incorporation into myoglobin heme. The uptake of radioiron was markedly enhanced by the addition of protoporphyrin and was moderately increased in the presence of $\delta$-aminolevulinic acid. Glycine plus succinate gave augmentation in muscle brei. In these respects, the results obtained with muscle extracts closely resemble those found with avian erythrocytes $(14,15)$. In other ways, as well, the similarity between muscle extracts and other tissues is striking. The optimal protoporphyrin concentration, the $\mathrm{pH}$ of optimal activity, the augmentation by cysteine, and the inhibition by sulfhydryl inhibitors all parallel results obtained with nucleated erythrocytes $(14,15)$ and liver (4). These findings are in keeping with the hypothesis that the mechanism for heme synthesis, which has been best demonstrated in avian erythrocytes, is a general mechanism (16), with only minor differences from tissue to tissue.

TABLE V

Effect of glycine and succinate on radioiron uptake in dog muscle brei

\begin{tabular}{lc}
\hline \hline & $c p m / \mu g . F e$ \\
\hline Brei control & 7 \\
Brei + protoporphyrin & 59 \\
Brei + glycine, $5 \times 10^{-2} \mathrm{M}$ & 39 \\
Brei + glycine, $5 \times 10^{-2} \mathrm{M}$ & 57 \\
and succinate, $5 \times 10^{-2} \mathrm{M}$ & 57 \\
\hline
\end{tabular}

Since the majority of the present studies were carried out at the step in myoglobin synthesis involving the incorporation of iron into heme, certain comments are in order concerning the evidence that the process demonstrated in muscle extracts is an enzymic one. It has been stated that, under conditions in which protoporphyrin is not in a colloidal state, chemical, nonenzymic insertion of iron can occur to form heme $(17,18)$. Several observations suggest that this was not the case in the present studies. First, heat and minimal concentration of potassium cyanide and parachloromercuriphenylsulfonic acid inhibited radioiron incorporation. Second, the supernatant solution obtained after ultracentrifugation, which contained amounts of myoglobin, protoporphyrin and radioiron like those present in whole extract, was much less active than either whole extract or residue. It should be noted also that controls consisting only of iron and protoporphyrin yielded practically no heme under the conditions of these experiments (Table II). Finally, the finding of

TABLE VI

Radioiron incorporation in myoglobin of human subjects

\begin{tabular}{|c|c|c|c|}
\hline Diagnosis & Control & $\begin{array}{c}\text { With } \\
\text { proto- } \\
\text { porphyrin } \\
1 \times 10^{-5} \mathbf{M}\end{array}$ & $\begin{array}{c}\text { With } \\
\text { proto- } \\
\text { porphyrin } \\
\text { and } \\
\text { cysteine } \\
1 \times 10^{-2} \mathbf{M}\end{array}$ \\
\hline Nondystrophic & $(\mathrm{cpm} / \mu \mathrm{g} . \mathrm{Fe})$ & $(c p m / \mu g . F e)$ & $(c p m / \mu g . F e)$ \\
\hline E. T. & 4 & 10 & \\
\hline \multicolumn{4}{|l|}{ Nondystrophic } \\
\hline E. $\mathrm{H}$. & 10 & 25 & 50 \\
\hline \multicolumn{4}{|c|}{ Myotonic dystrophy } \\
\hline A. L. & 7 & 16 & \\
\hline \multicolumn{4}{|c|}{ Myotonic dystrophy } \\
\hline R. H. & 1 & 5 & \\
\hline
\end{tabular}


optimal activity at a $\mathrm{pH}$ near neutrality with lower activity on each side of this optimum is in accord with the conclusion that the process is an enzymic one.

With the exception of one extract from nondystrophic muscle, only low levels of radioactivity were obtained with human muscle. The autolysis which had occurred in the long periods that had elapsed between death and study of radioiron uptake may have been responsible for the low levels of uptake. In each instance, however, protoporphyrin increased the incorporation of radioiron into myoglobin. In addition, cysteine was found to augment this process further, in one instance. It seems reasonable to conclude, therefore, that radioiron incorporation into myoglobin heme occurred in muscle extracts from all these patients. Within these limitations, no differences were observed between dystrophic and nondystrophic muscle.

\section{SUM MARY}

1. Radioiron was incorporated into the heme of myoglobin in the supernatant solutions from dog muscle homogenates.

2. Protoporphyrin and $\delta$-aminolevulinic acid augmented the incorporation of radioiron. Cysteine and reduced glutathione were also found to increase radioiron uptake. Glycine plus succinate augmented radioiron uptake in muscle brei.

3. Heat, potassium cyanide and parachloromercuriphenylsulfonic acid inhibited this process.

4. The conditions which favor iron incorporation into myoglobin heme closely resemble those known to favor heme biosynthesis in other tissues.

5. Preliminary observations suggest that extracts from both normal and dystrophic human muscle are capable of carrying out this process.

\section{REFERENCES}

1. Shemin, D., London, I. M., and Rittenberg, D. In vitro synthesis of heme from glycine by nucleated red blood cells. J. biol. Chem. 1948, 173, 799.

2. Goldberg, A., Ashenbrucker, H., Cartwright, G. E., and Wintrobe, M. M. Studies on the biosynthesis of heme in vitro by avian erythrocytes. Blood 1956, 11, 821.
3. Altman, K. I., Salomon, K., and Noonan, T. R. Hemin synthesis in rabbit bone marrow homogenates. J. biol. Chem. 1949, 177, 489.

4. Minakami, S., Yoneyama, Y., and Yoshikawa, H. On the biosynthesis of heme and hemoproteins in liver cell. Biochim. biophys. Acta 1958, 28, 447.

5. Shemin, D. The succinate-glycine cycle: The rôle of $\delta$-aminolevulinic acid in porphyrin synthesis in Ciba Foundation Symposium on Porphyrin Biosynthesis and Metabolism, G. E. W. Wolstenholme and E. C. P. Miller, Eds. London, J. and A. Churchill, Ltd., 1955, p. 4.

6. Neuberger, A., and Scott, J. J. Aminolaevulinic acid and porphyrin biosynthesis. Nature (Lond.) 1953, 172, 1093.

7. Falk, J. E., Dresel, E. I. B., and Rimington, C. Porphobilinogen as a porphyrin precursor, and interconversion of porphyrins, in a tissue system. Nature (Lond.) 1953, 172, 292.

8. Perkoff, G. T., Brown, D. M., and Tyler, F. H. The isolation of myoglobin in progressive muscular dystrophy. J. clin. Endocr. 1957, 17, 1489.

9. Perkoff, G. T., and Tyler, F. H. Estimation and physical properties of myoglobin in various species. Metabolism 1958, 7, 751.

10. Schwartz, H. C. Unpublished observations.

11. Gubler, C. J., Lahey, M. E., Chase, M. S., Cartwright, G. E., and Wintrobe, M. M. Studies on copper metabolism. III. The metabolism of iron in copper deficient swine. Blood 1952, 7, 1075.

12. Fischer, H. Organic Synthesis. New York, Wiley and Sons, 1941, vol. 2, p. 53.

13. Shemin, D., London, I. M., and Rittenberg, D. The synthesis of protoporphyrin in vitro by red blood cells of the duck. J. biol. Chem. 1950, 183, 757.

14. Schwartz, H. C., Cartwright, G. E., Smith, E. L., and Wintrobe, M. M. Studies on the biosynthesis of heme from iron and protoporphyrin. Blood 1959, 14, 486.

15. Krueger, R. C., Melnick, I., and Klein, J. R. Formation of heme by broken-cell preparations of duck erythrocytes. Arch. Biochem. 1956, 64, 302.

16. Theorell, H., Beznak, M., Bonnichsen, R., Paul, K. G., and Akeson, A. On the distribution of injected radioactive iron in guinea pigs and its rate of appearance in some hemoproteins and ferritins. Acta chem. scand. 1951, 5, 445.

17. Granick, S., and Mauzerull, D. Porphyrin biosynthesis in erythrocytes. II. Enzymes converting $\delta$-aminolevulinic acid to coproporphyrinogen. $\mathrm{J}$. biol. Chem. 1958, 232, 1119.

18. Heikel, T., Lockwood, W. H., and Rimington, C. Formation of non-enzymatic haem. Nature (Lond.) 1958, 182, 313. 